\title{
Cuban Maternity Homes: A Model to Address At-Risk Pregnancy
}

\author{
Conner Gorry MA
}

Like a tropical lullaby, the rocking chairs lay down a languid rhythm accompanied by laughter, bits of gossip, and gripes about the heat. Olga Lydia, 39 , anemic, and preparing to give birth to her first child, wonders aloud what it will be like to have a son, when in her heart of hearts she wanted a daughter. Meanwhile, Loreta, 18, and expecting twins, rocks quietly alongside, a smile on her flawless face.

Olga Lydia and Loreta are two of the more than 67,000 at-risk expectant mothers[1] served by $\mathrm{Cu}$ ba's network of over 300 maternity homes, receiving comprehensive care and childbirth education in either live-in or ambulatory modalities. Since the first 15 such homes were founded in 1962 in the eastern part of the country, the system has evolved into a national program employing a uniform practice for women presenting certain risk factors during pregnancy. The strategy has helped the country achieve a nearly $100 \%$ in-hospital birth rate[2] and lower infant and maternal mortality rates, and partly explains why Save the Children ranks Cuba as the number one developing country in which to be a mother.[3]

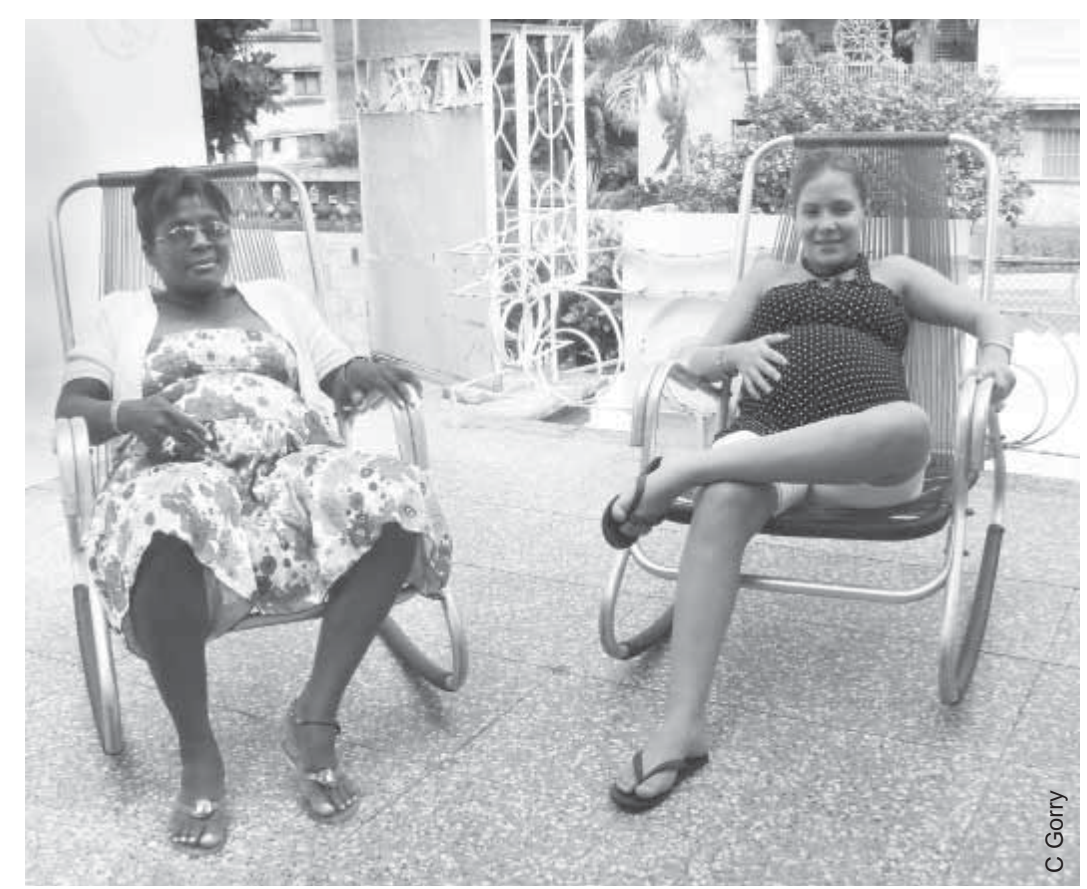

Olga Lydia and Loreta: comprehensive care addresses individual risk factors.

\section{Fostering Equity, Facilitating Access}

Prior to 1959, fewer than $20 \%$ of all births in Cuba were in hospitals.[4] Most of these institutions, like all health services, were concentrated in cities. Lack of roads in mountainous areas made childbirth especially treacherous there. Thus, women in remote regions faced the worst prognosis, where they often made "long trek[s] to the hospital...incurred labor and delivery complications en route and died."[5] In the initial stages of the maternity home program in the 1960s, the single criterion for referral was geographic, with expectant mothers from remote rural areas living in maternity homes located near hospitals for all or part of their pregnancy.

Rather than embed these facilities in traditional health care settings, existing houses were re-purposed and re-conditioned to create a familiar, home-like environment where the health and wellbeing of mother and fetus could be monitored. By providing basic medical services, physical and recreational activities, and health promotion and education in a comfortable setting, the aim was for "expectant mothers to reach their delivery date in optimal health," says Dr Myrna Ortega of the National Obstetrics and Gynecology Group, former coordinator of the maternity homes program, and now advisor to the Ministry of Public Health's Maternal-Child Department.

The strategy worked. These first maternity homes, together with aggressive training of doctors and other health professionals and an increase in the number of maternity hospitals, had a significant early impact on maternal and infant mortality (Table 1). Such results motivated Cuba to expand the maternity home system: by 1989 — when the neighborhood family doctor-nurse program had been firmly established-there were 150 maternity homes across the island, and over $98 \%$ of births were in hospitals.[6] At that point, criteria for admission had also evolved to include other risk factors besides distance from the nearest hospital.

Another stage in the program began in the 1990s during Cuba's severe economic crisis, when generalized food scarcity translated into insufficient weight gain for many pregnant women and a corresponding increase in rates of low birthweight newborns: low birthweight newborns were $7.3 \%$ in 1989 , but that figure had jumped to $9 \%$ by 1993 . This crisis spurred several innovations in

Table 1: Maternal and Infant Mortality in Cuba, Selected Years

\begin{tabular}{|l|c|c|}
\hline Year & $\begin{array}{c}\text { Maternal mortality ratio } \\
\text { (per 100,000 live births) }\end{array}$ & $\begin{array}{c}\text { Infant mortality } \\
\text { (per } \mathbf{1 0 0 0} \text { live births) }\end{array}$ \\
\hline $1957^{\mathrm{a}}$ & NA & 37.6 \\
\hline $1962^{\mathrm{b}}$ & 117.9 & 41.5 \\
\hline $1967^{\mathrm{b}}$ & 90.1 & 36.4 \\
\hline $1972^{\mathrm{b}}$ & 52.0 & 28.7 \\
\hline $1982^{\mathrm{b}}$ & 48.2 & 17.3 \\
\hline $1992^{\mathrm{b}}$ & 33.0 & 10.2 \\
\hline $2003^{\mathrm{c}}$ & 39.5 & 6.3 \\
\hline $2010^{\mathrm{d}}$ & 43.1 & 4.5 \\
\hline
\end{tabular}

NA: not available

Sources: a United Nations, Demographic Yearbook: Historical Supplement, 1979, NY, United Nations, pp 93-100; 'bos hogares maternos de Cuba. Cuadernos de Historia de la Salud Pública. Havana: Ministry of Public Health (CU); 2007, pp11; ${ }^{c}$ Ministry of Public Health (CU), National Statistics Division. Anuario Estadístico de Salud 2005; ' Ministry of Public Health (CU), National Statistics Division. Anuario Estadístico de Salud 2010. 
the maternity home model, including more emphasis on nutrition and diet, relying on closer collaboration with small farmers and local workplaces to ensure healthy meals; cooperation with the Federation of Cuban Women to assist maternity home staff and outreach; and provision of ambulatory services allowing women to take their meals and classes at the facility, but return home in the evenings.

By 1996, low birthweight babies once again constituted only $7.3 \%$ of the total, and the percentage continued to decline over the rest of the decade, standing at 5.4 in 2010; infant mortality, which increased from 9.4 to 9.9 per 1000 live births between 1993 and 1994, began consistently decreasing, reaching 6.5 by 1999 and reaching 4.5 in 2010.[1]

\section{Current Approach}

Today, each of the 327 maternity homes across the country follow uniform practice guidelines designed by the Ministry of Public Health's Maternal-Child Health Program, in collaboration with UNICEF. Updated periodically, they have expanded criteria for admission, standardized intake forms, set out diagnostic and clinical guidelines for identifying risk factors, and established protocols for treatment in maternity home settings.

With the 2011 update currently being finalized, admission criteria include:

- Pregnant teens

- Anemia

- Nutritional deficiencies

- Obesity

- Multiple births

- Pre-eclampsia

- Hypertension and diabetes

- Risk factors for preterm labor

- Adverse social determinants, including geographic

- Women over 35 with any other risk factors

Diagnosis and referral processes are supported throughout the health system, beginning with each woman's neighborhood-based family doctor and community polyclinic, and including her obstetrician and the resources of the National Maternal-Child Health Program.

"What's especially important is early detection of at-risk pregnancies and transfer to a maternity home at the appropriate stage so that if complications arise, the mother is close to the services she and her baby need," explained Dr Ortega, coauthor of the practice guidelines.

Patient consent is required for admission. Typically, women enter maternity homes after 20 weeks of pregnancy and stay 8 weeks,[3] but this varies depending on their specific risk factors. Women with acute medical conditions requiring more specialized care are not referred to maternity homes but instead are admitted to hospitals, as are residents of maternity homes who become ill or whose condition worsens.[7]

\section{Caring for Mothers, Preparing for Birth}

Whether she hails from inner city Havana or the remote Sierra Maestra mountains, once a woman steps through the doors of a maternity home, she receives comprehensive care from a multidisciplinary team. This includes an obstetrician, psychologist, clinical nutritionist and dietician, internist, dentist, and fitness trainer. Round-the-clock care is provided by specially trained nurses (in larger homes this may be a family doctor) who serve as a link in the continuum of care across levels of the health system. Their presence ensures constant monitoring of fetal development and the woman's progress, adherence to diet, medications, and exercise, and compliance with specialist recommendations.

A series of assessments and exams are conducted upon admission, including a full dental check up. This is important, since maternal oral infections have shown to be a reliable predictor of low birthweight.[8] Because getting Cubans into a dental chair can be like pulling teeth, maternity home dentists not only treat infections, but also fill cavities, do routine cleanings, and provide other necessary dental services for the duration of the woman's stay.

Another fundamental step in the admission process is an in-depth nutritional analysis. Using the woman's clinical history, body mass index, mid-upper arm circumference measurement, and body weight, the nutritionist designs a diet based on the FAO and WHO recommendations for caloric, vitamin, and mineral intake for pregnant and lactating women, adjusted for Cuban norms and the individual needs of each woman.

The diet defines how many calories each woman should be consuming daily (2300-3500); what percentage should be protein, fat or carbohydrates; and how the food should be prepared (e.g. low sugar and salt, nothing fried, etc.). Details of each woman's diet is discussed with the cooks, to ensure variety, and posted in the kitchen. Progress is monitored and adjustments are made through weekly consultations between patients and their dietician. "I eat every three hours and get milk or yogurt four times a day," mother-to-be Janet Milián told MEDICC Review on a recent visit to a Havana maternity home. "Sometimes I can't eat it all!"

Each woman's vital signs are checked twice daily, and her abdominal circumference and weight are measured every day. Fitness trainers lead exercise classes twice a week and psychologists hold regular counseling sessions with women requiring or requesting them. "The role of the psychologist is crucial since pregnancy is a time of heightened sensitivity and can bring on psychological difficulties-sometimes creating a family crisis once mother and baby move back home," says Dr María Julia Saenz, Director of the Ismaelillo Maternity Home in the Nuevo 


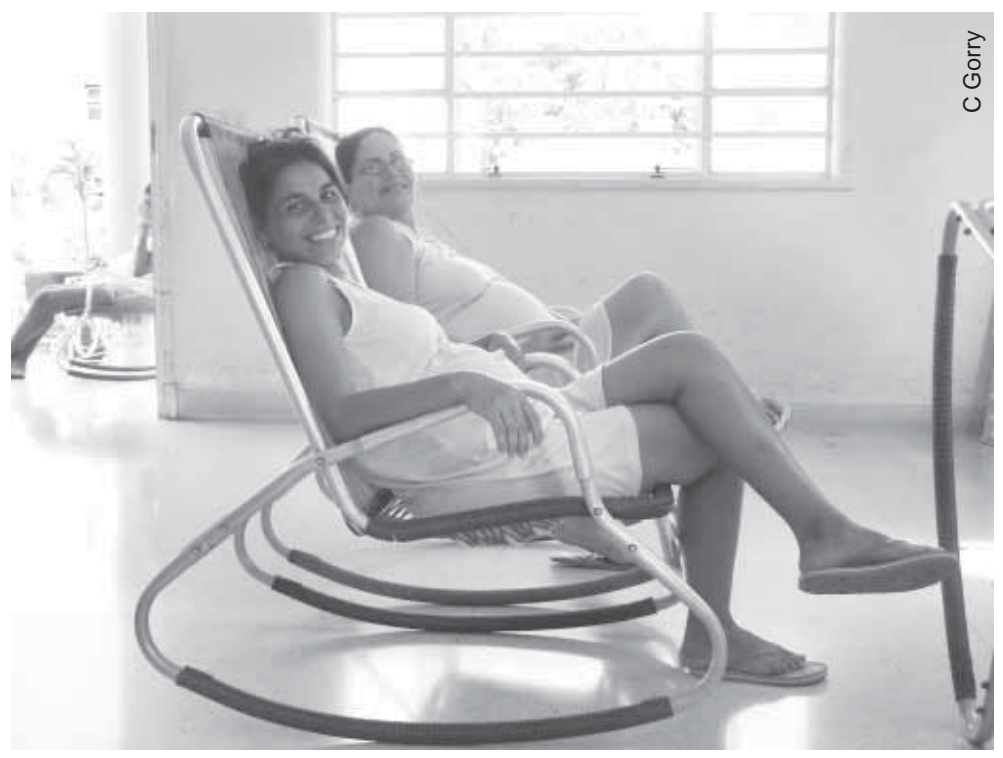

Janet and Natasha at the Ismaelillo Maternity Home, Havana. appropriate-whereas older women may favor a knitting class, the younger generation might favor pop music and dancing.

\section{Challenges Ahead}

While infant mortality is now under 5 per 1000 live births-comparable to rates in industrialized countries[9] —and low birthweight newborns are just 5.4\%,[1] Cuban health authorities and professionals are less satisfied with progress in consistently reducing maternal mortality. In 2010, the maternal mortality ratio was 43.1 (per 100,000 live births); 29.7 in direct maternal mortality, and 13.3 indirect-well below the 85 registered in 2008 for Latin America and the Caribbean, but still considered unsatisfactory.[10] This has led to a national review of protocols, facilities, human resources, and preventive approaches in order to achieve further reduction of maternal deaths. Women's education about their own bodies, better identification by the health system of at-risk women, and concentration of high-tech resources where they are most needed are some of the responses already being implemented.
Vedado neighborhood of Havana. "Preparing the couple to welcome a new member into their family is an important aspect of our work."

Social workers also form an integral part of the maternity home team, particularly when women are admitted due to social circumstances including lack of family support for the pregnancy, an overcrowded home, and apparent gender or other inequities within the family unit. In these cases, social workers carry out educational activities with the woman and her family and together with the maternity home psychologist, make home visits for family therapy sessions and related educational and health promotion activities. "The goal is that when the mother returns home with her newborn, she'll find a harmonious environment. But it's hard work and modifying behavior is a slow process," said Dr Ortega.

During their stay, expectant mothers have extensive educational opportunities-many of which involve their partners-such as 'Preparing for Birth' workshops where both parents learn breathing and other birthing techniques; classes on breastfeeding and ante- and post-natal care; and HIV prevention activities. Women also learn about family planning and receive legal counsel, again with their partner, about their rights to maternity and paternity leave, legal responsibilities of parenthood, and other topics. "The mission of maternity homes isn't only to bring women to term in the best health possible, but also to prepare them for motherhood and that first crucial year of life," said Dr Saenz, underscoring the importance of maternity homes' educational and health promotion functions. "We involve their partners early on in the process to help create a strong family bond," she explained.

Although each maternity home follows standardized guidelines, there is flexibility and room for an individualized approach. Pregnant teens, for instance, receive differentiated care since their bio-psychosocial needs can differ dramatically from other maternity home residents. Among other things, this means family planning and HIV prevention materials are tailored to appeal to this younger group, and recreational activities strive to be age-
The maternity homes are now called upon to play a greater role as this process moves forward. As with health services generally across the country, they are also undergoing reorganization to both cut costs and better reflect the health picture of individual communities-while aiming to improve service quality and efficiency. No easy feat.

In particular, this has meant closing some smaller maternity homes with 8 to 10 underutilized beds and enlarging others to 20 beds or more, so as to maintain the same number of available beds-currently over 7,000 across the country.[11] Yet, the process is not a seamless one, and the newly available facility may not be as close to home and family as before. New solutions are needed and being forged. "Where homes are being closed, the driving principle is to locate at-risk pregnant women close to specialized maternity hospitals," explains Dr Ortega. "The advantage is not just fiscal savings, since this proximity allows for specialist consultations, access to the latest technology, and other services the women may need." Regular maternity home team evaluations, complemented by satisfaction surveys completed by all patients and their families, are identifying more areas for improvement.

In the Ismaelillo Maternity Home in Havana, as in others throughout Cuba, doctors, nurses, and support staff meet monthly to assess their work and design a plan of action to address problems.

Home residents are invited to weigh in with their concerns at these meetings, in addition to completing the satisfaction surveys. The purpose of the qualitative and quantitative survey is to "improve the quality of care offered during this wonderful stage of life."[7] Questions_ranging from quality of medical treatment and level of privacy to comfort of the beds and adequacy of lighting and ventilation-are answered on a scale of 1 to 5 ( 1 as poor, 5 as excellent).

One area under continual evaluation is the frequency and type of recreational activities offered in maternity homes, since 
boredom can become a serious challenge for women admitted during the early stages of their pregnancy. Community involvement is pivotal to this effort, with members of local seniors clubs offering sewing and knitting classes for example, or neighborhood musicians giving concerts, as happened during MEDICC Review's recent visit to the Ismaelillo Maternity Home. "I read, I rest, I watch TV and talk with the other women," said Janet Milián, in her $28^{\text {th }}$ week of pregnancy, when asked how she combated boredom.

Over its nearly 50-year trajectory, Cuba's community-based maternity home network has been found a cost-effective approach contributing to reductions in infant and maternal mortality, and in incidence of low birthweight newborns.

Perhaps the day will come when staving off boredom is the biggest worry for pregnant women the world over-especially for expectant mothers in the Global South, where maternal mortality still stands at nearly 300 per 100,000 live births[10] with infant mortality in 2009 running as high as 134 per 1000 live births in Afghanistan and up to 126 in Sub-Saharan Africa. $-1 /$

\section{References \& Notes}

1. Ministry of Public Health (CU), National Statistics Division. Anuario Estadístico de Salud 2010. Havana: Ministry of Public Health (CU); 2011 Apr. Spanish.

2. National Statistics Bureau (CU). Anuario Demográfico de Cuba 2010. Havana: National Statistics Bureau (CU); 2010. Spanish.

3. Save the Children. State of the World's Mothers 2011. Westport (US): Save the Children Federation Inc.; 2011.

4. Ramos Domínguez BN, Valdés Llanes E, Hadad Hadad J. Hogares Maternos en Cuba: Su evolución y Eficiencia. Rev Cubana Salud Pública. 1991 JanJun;17(1):4-14. Spanish.

5. Pérez A. Maternity Homes in Cuba [unpublished master's thesis].

6. Gutiérrez J, Delgado G. Los hogares maternos de Cuba. Cuadernos de Historia de la Salud Pública. Havana: Ministry of Public Health (CU); 2007. Spanish.

7. Santana MC, Ortega M, Cabezas Cruz E. Metodología de los hogares maternos 2007. Havana: Ministry of Public Health (CU); 2007. Spanish.

8. Offenbacher S, Katz V. Fertik G, Collins J, Boyd D, Maynor G et al. Periodonta infection as a possible risk factor for preterm low birth weight. J Periodonto [Internet]. 1996 Oct [cited 2011 Jun 25 ];67(10 Suppl):1103-13. Available from: www.joponline.org/doi/abs/10.1902/jop.1996.67.10s.1103.

9. United Nations Statistics Division. Millennium Development Goals Indicators [Internet]. New York: United Nations; 2000 [updated 2011 Jul; cited 2011 Jul 15]. Available from: http://unstats.un.org/unsd/mdg/Default.aspx

10. United Nations. Millennium Development Goals Report 2010, Addendum 2 [Internet]. New York: United Nations; 2010. [cited 2011 Jun 25]. Available from: http://www.un.org/millenniumgoals/pdf/MDG\%20Report\%202010\%20En\%20 r15\%20-low\%20res\%2020100615\%20-.pdf.

11. Interview with Dr Myrna Ortega Blanco, June 23, 2011.

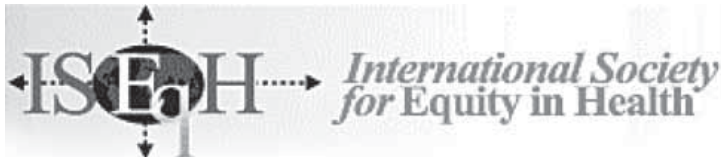

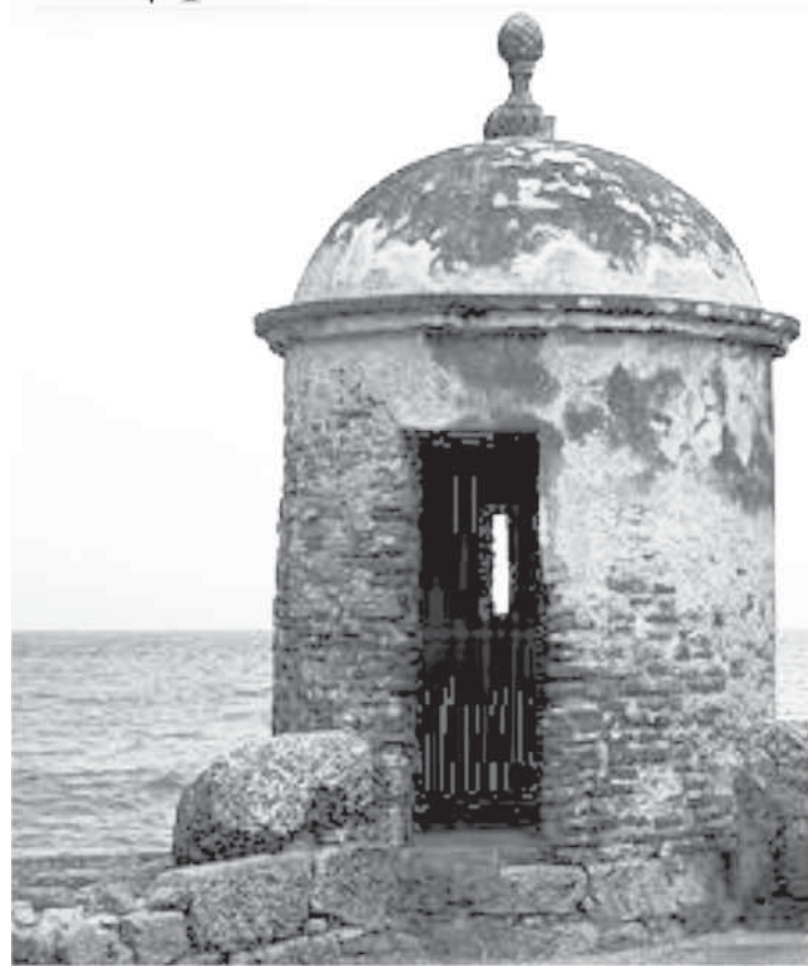

6th INTERNATIONAL CONFERENCE Making policy a health equity building process Sept. 26-28, 2011 University of Cartagena/Hotel Caribe Cartagena, Colombia 